June 1995

\title{
Concepts and Models of Empathy: Past, Present, and Future
}

\author{
Elizabeth Ann Baxter, MD \\ University of Rochester, Rochester, New York
}

Follow this and additional works at: https://jdc.jefferson.edu/jeffjpsychiatry

Part of the Psychiatry Commons

Let us know how access to this document benefits you

\section{Recommended Citation}

Baxter, MD, Elizabeth Ann (1995) "Concepts and Models of Empathy: Past, Present, and Future," Jefferson Journal of Psychiatry. Vol. 12 : Iss. 2 , Article 4.

DOI: https://doi.org/10.29046/JJP.012.2.001

Available at: https://jdc.jefferson.edu/jeffjpsychiatry/vol12/iss2/4

This Article is brought to you for free and open access by the Jefferson Digital Commons. The Jefferson Digital Commons is a service of Thomas Jefferson University's Center for Teaching and Learning (CTL). The Commons is a showcase for Jefferson books and journals, peer-reviewed scholarly publications, unique historical collections from the University archives, and teaching tools. The Jefferson Digital Commons allows researchers and interested readers anywhere in the world to learn about and keep up to date with Jefferson scholarship. This article has been accepted for inclusion in Jefferson Journal of Psychiatry by an authorized administrator of the Jefferson Digital Commons. For more information, please contact: JeffersonDigitalCommons@jefferson.edu. 


\title{
Concepts and Models of Empathy: Past, Present, and Future
}

\author{
Elizabeth Ann Baxter, M.D.
}

\begin{abstract}
The subject of empathy has been increasing in popularity and importance; correspondingly, the theoretical aspects of empathy are in need of further development. This paper outlines key concepts and processes related to empathy, particularly the mechanisms of identification and regression as they are discussed in the models of empathy articulated by Fleiss, Greenson, and Jordan. Similarities and differences of the models are examined, in addition to each model's description of the roles of identification and regression. Although each model has made significant contributions towards a theoretical perspective of empathy, none of them have distinguished pathological from non-pathological uses of identification. Also, none of the models offered descriptions of the pathological or non-pathological uses of regression in empathy. In response to these differences, a new model of empathy is proposed. This new model emphasizes the non-pathological roles of identification and regression, which make empathy a creative process involving a therapist's highly developed ego and ego functions.
\end{abstract}

The subject of empathy has been increasing in popularity and importance with the development of psychotherapy theories such as self-psychology (1) and self-inrelation (2). However, the concept of empathy was initially seen in the professional literature at the turn of the century, when Titchner translated Einfühlung as to "feel" or "find" one's way into another's experience (Babineau, R. The Empathetic Mode in Psychotherapy. Rochester, 1993). Sigmund Freud (5) also recognized the importance of empathy in psychotherapy. He stated that. . . "A path leads from identification by way of imitation to empathy, that is, to the comprehension of the mechanism by means of which we are enabled to take up any attitude at all towards another mental life" (1912, p. 110). However, much of the literature on empathy is scattered diffusely throughout a vast number of works. Greenson (4) comments that analysts often either take empathy for granted or underestimate it. He noted some antagonism between empathy and theory, as theoreticians neglect the area of empathy while empathic clinicians write little theory.

There remain many questions, areas of disagreement, and burgeoning ideas related to the concept of empathy. In this paper, I will attempt to help the reader understand key concepts and processes related to empathy, particularly the mecha-

Elizabeth Ann Baxter, M.D. recently completed her psychiatric residency at the University of Rochester in Rochester, New York. 
nisms of identification and regression as they are discussed in three recognized models of empathy. These models include those of Fleiss (5), Greenson (4), and Jordan (6). After a review and critique of these models, I will introduce my own model of empathy and explain the non-pathological roles of identification and regression included in this model.

\section{CONCEPTUAL DEVELOPMENT OF MODELS OF EMPATHY}

Theorists have conceptualized empathy in many ways throughout this century. Freud (7) saw it as the origin of comic pleasure and also as central to the process of psychoanalysis. Fleiss described empathy as putting oneself into another's place, or to "step into his [another's] shoes" (1942, p. 212). Winnicott (8) associated empathy with the infant's early holding environment created by the mother "feeling" the infant's needs. This environment must be reliable, protect the infant from excessive annihilation fears, and involve physical holding. Greenson (4), one of the first ego psychologists to write in the second half of this century about the central role of empathy in psychotherapy, thought of empathy as emotional knowing or the experiencing of another's feelings. His seminal paper "Empathy and its Vicissitudes" (1960) served as a focal point in the history of empathy literature because he gave insight into the therapist's experience of the empathic process. Greenson provided a detailed discussion of identification with his patient, while he outlined the "working model" of the patient and the sequence of events involved in the empathic process (9).

Empathy also served as the central focus in self-psychological theory introduced by Heinz Kohut. In his 1959 paper, "Introspection, Empathy, and Psychoanalysis," Kohut described empathy as "vicarious introspection" and described it as an essential constituent of all psychological observations. He stated that empathy defined the field of depth psychology, and unlike Freud, believed that the classic tools of free association and analysis of resistances were only auxiliary instruments used in the service of introspection and empathy (1).

Other theorists such as Wolf, Basch and Nadelson have further developed Kohut's ideas about empathy. Wolf (10) summarized Kohut's thoughts regarding empathy as: a) serving to define the field of depth psychology, b) a processing function to obtain information during the process of psychotherapy, and c) a self-sustaining function to help the person feel better by minimally sharing his/her feelings. Basch, (11) further described the process of vicarious introspection as: a) recognizing the therapist's affective response to the patient, b) decentering his/her affective reaction, and c) identifying the patient's affective state following this interchange.

Nadelson has remembered Kohut's view of empathy as "a fundamental mode of human relatedness ... the recognition of the self in the other ... the accepting, confirming and understanding human echo ... the resonance of essential human alikeness" (12). 
A number of other contemporary theorists have articulated their own perspectives about the nature of empathy. Hamilton (13) stated that empathy serves to hold and contain the therapeutic relationship by allowing the therapist to understand the patient, and also serves an interpretive function. Jordan (6) described empathy as having both affective and cognitive aspects expressed as a complex intellectual and emotional process. Finally, Rogers (14) wrote about the role of empathy in the psychotherapeutic relationship, noting those relationships based on empathic understanding correlated with successful therapeutic outcome. In Rogers' system, the most helpful therapist procedure involved the therapist clarifying and openly stating feelings which the client had been approaching hesitantly. In an empathic therapeutic relationship, Rogers described the therapist as: a) genuine and transparent, b) accepting and prizing of the uniqueness of the other person, and c) sensitively seeing the patient and his/her world as the patient does.

Rogers proposes that if these above characteristics are present, the client will experience positive therapeutic change. He states that empathic understanding is present when the therapist is sensing the feelings and personal meanings which the client is experiencing in each moment, when he can perceive these from "inside as they seem to the client" (14).

\section{FLEISS' MODEL OF EMPATHY}

Fleiss (5) labeled empathy a trial identification and described its process as involving four distinct parts. First, the analyst is the object of the patient's striving. Next, he/she identifies with the patient, and becomes the patient. After experiencing the patient's striving, the analyst projects it back onto the patient with inside knowledge of its nature. From this process, the analyst has acquired the emotional basis for his/her interpretation.

Prior to Fleiss' description of empathy, other theorists had conceptualized empathy as involving an oscillation between two perspectives. Freud said that the therapist must maintain a "suspended even-hovering attention" to the therapeutic process (7). This suspension was to occur between the perspectives of observation and introspection. The idea of empathy occurring as an oscillation between two perspectives is a cornerstone for later models. Fleiss includes this oscillation as he describes movement from the analyst's perspective to that of the patient, and then back again to the analyst. In his model, he uses the process of identification as well as the process of projecting back inside knowledge of the patient's experience. While Fleiss does not further define his use of identification, it appears to serve a defensive function related to incorporation of external objects by eating or swallowing (5). Fleiss does not comment on any use of regression in his model of empathy. By organizing ideas about identification and that of oscillation into one model of empathy, Fleiss' contribution has historical significance which is reflected in later models of empathy. 


\section{GREENSON'S MODEL OF EMPATHY}

Greenson (4) articulates another model of empathy that is very experiential in nature. He states that the therapist feels initially "out of it" in the therapeutic situation, but gradually allows him/herself to become the patient. The therapist then listens through the "working model" of the patient by listening to the patient's words, and then transforming them into pictures and feelings from the patient's memories. The therapist uses his/her own experiences similar to the patient to make emotional contact and experiences a feeling of "aha." Finally the therapist determines how best to communicate this understanding to the patient.

Greenson's concept of the "working model" is critical in his description of empathy, as it provides a lens through which he can connect with the patient and accurately understand. To build this working model, he begins with everything known of the patient, including experiences, behaviors, memories, fantasies, dreams, defenses, and resistances. As resistance is diminished, the therapist's theoretical knowledge, clinical experience, and view of the patient's potentials are added. Finally, the therapist adds his/her experiences with similar people and situations (4).

Greenson's model of empathy is based on his own self-observation which he has painstakingly described. He allows the reader to experience with him in detail his process of connection with the patient. In addition, Greenson oscillates from observer to participant, and back to observer as he "feels out of it," listens, makes emotional contact, then understands.

Greenson states identification is different from empathy, yet still closely-related. While identification is "unconscious and permanent," empathy is "preconscious and temporary" (4). According to Greenson, identification serves a time-limited defensive function in that he temporarily "becomes the patient" during the empathic process. He makes no comment on any use of regression in his model of empathy.

\section{JORDAN'S MODEL OF EMPATHY}

Jordan (6) articulates a more contemporary model of empathy. She says the process starts with a motivation towards relatedness with another and involves a surrender of one's affective arousal in response to the other. Next, there is a temporary identification with the other. Simultaneously, one knows the source of affect is in the other. After temporary identification with the other, the affect subsides into an increased feeling of separateness. From this process, one has the ability to help the other understand his/her world better.

Jordan (6) states that while temporary identification is occurring, the person experiencing it is also aware that the source of affect is in the other. Thus, Jordan conceptualizes empathy as having cognitive and affective parts. This dualistic nature of empathy allows an affective connection (identification) to occur simultaneously with a cognitive separateness (source of affect as in the other) (6). Similarly, other authors have discussed the process of empathy as being both detached and involved 
(4). Jordan, however, disagrees with the use of regression in empathy in other parts of her writing. Further scrutiny of her writings and personal communication (1994) show that she understands regression to be represented by writers and clinicians primarily as a defensive and pathological process.

\section{SUMMARY OF MODELS}

Before examining the similarities and differences among the three main models of empathy and offering a critique of these models, I will briefly summarize the key concepts addressed by Fleiss, Greenson, and Jordan in their representative models.

Fleiss (5) introduced the process of identification in empathy ("trial identification") via "becoming" the patient. After gaining understanding of the patient, the analyst projects this understanding back to the patient. Fleiss uses the oscillation between observer-participant-observer in his description.

Greenson's (4) model presents in detail the therapist's experience of empathy. His description of the working model is a central part of this experience. As he oscillates from observer to participant to observer, he speaks of his reactions to the patient progressively. An "aha" is reached, and he communicates this understanding to the patient.

Jordan (6) describes an initial "surrender of affective arousal," leading to a "temporary identification." Through affective connection with and cognitive separateness from the other, one can help the other understand his/her world better.

\section{SIMILARITIES, DIFFERENCES, AND CRITIQUE OF MODELS}

Greenson and Fleiss describe the therapist "becoming another" which takes an almost literal view of the traditional and defensive definition of identification. However, Greenson also views identification as serving a non-defensive function when he describes it as "temporary and preconscious." He is detailed and non-traditional in his description of the therapist's experience of empathy. Jordan also denotes identification as "temporary" and as serving a non-defensive function. Jordan, Greenson, and Fleiss all follow the concept of oscillation from observer to participant to observer. Also, all ascribe an important role to the concept of identification in empathy. While Greenson \& Fleiss do not comment on the use of regression in empathy, Jordan clearly disagrees with its use in pathological terms. All of these models contribute important ideas to a model for empathy, yet they fail to fully address the non pathological roles of identification and regression in the empathic process. These deficiencies suggest areas for future theory development and clarification.

\section{A NEW MODEL OF EMPATHY}

After reviewing the empathy literature and three main models of empathy, I suggest a new model of empathy which involves the non-pathological processes of 
regression and identification as crucial parts of the empathic process. I propose the following model of empathy:

1. Following a desire for connection, one regresses in order to be influenced affectively by another person's affect.

2. Identification with that person occurs affectively, while remaining cognitively separate. This occurs in a fluid and oscillating manner.

3. The regression reverses so that one becomes affectively separate.

4. One uses what is learned in the identification process to share with the other person one's understanding of his/her world.

This model shares similarities with that of Jordan's and utilizes the historical concept of observer-participant-observer oscillation. My model introduces the use of regression in a non-pathological manner, allowing one to understand better the transition between observer and participant.

\section{IDENTIFICATION AND EMPATHY}

In addition to its defensive function, the process of identification plays an important role in learning and empathy throughout the normal life cycle. As a child, one constantly experiences the loss of a loved object or of a significantly gratifying relationship with the object, usually a parent. As the child develops, he/she loses types of gratification which were appropriate to the previous phase of maturation. The child tries to retain the lost gratification by identifying with aspects or qualities of the person who was once the source of these gratifications. These internalized aspects of the other person are then re-established as part of the developing ego. Freud in fact described the ego as composed of the internalizations from abandoned object-cathexis (16).

Melanie Klein stated that identification plays a fundamental role in development throughout the course of one's life. Highly cathected people, such as lovers and spouses, associated with love and not loss, may be the focus of identification and strengthening of the ego. Wishes and unfulfilled fantasies of one's childhood related to unconscious mental processes are a part of normal mental functioning throughout one's life (16).

An examination of Piaget's learning theory of assimilation and accommodation may also be used to further understand identification. Assimilation involves the incorporation of external reality by a self, producing judgement in the self. Accommodation, on the other hand, involves testing what is learned from assimilation, or the self relating to external reality. Identification can be seen as part of assimilation, as the person in question takes in part of the external reality and becomes like it (17).

Piaget has disagreed with equating assimilation and identification, saying that assimilation is more than identification. Assimilation produces new structures only in conjunction with accommodation, making their interdependence essential. Furthermore, the understanding of relationships and their reciprocity, as gathered from the assimilation-accommodation process, is the cornerstone of learning. This complex 
and dynamic interchange cannot be represented simply by the concept of identification. The processes of assimilation and identification, however, do share some similarities. Both can be useful in understanding the process of empathy. By taking in information from another, both affectively and cognitively, one can learn about the other and test this learning through interpretation of the other's experience.

\section{REGRESSION AND EMPATHY}

Similar to identification, the mechanism of regression plays an important role in the process of empathy and has both pathological and non-pathological significance. Regression has been defined as returning to an earlier phase of development to avoid the anxieties in the current phase (18). This definition conceptualizes regression in a defensive or pathological manner. Defensively, regression helps a person to emotionally stabilize in the presence of severe conflicts related to the wishes of earlier phases. Through regression, the wishes may be given up and the individual may return to wishes of earlier phases (16).

However, regression is also a normal part of mature adult life and serves a nondefensive function. Freud initially linked the processes of dreams, jokes, and errors of everyday life to temporary failures of regression. Another author has stated that these are not failures but rather normal psychic phenomena allowing pleasurable expression of wishes which have been defended against since childhood. Regression in the service of the ego, as termed by Kris, allows for the enjoyment of activities such as intellectual and artistic creativity, enjoyment of works of art and entertainment, religious activities, sports, recreational games, sexual intercourse, relaxation, and sleep $(18,19,20)$. Regression in these cases is reversible, controlled and must be regulated. The ability to control regression in such activities is due to strength in the ego and is regulated through voluntary and temporary withdrawal of cathexis from one of many areas. When regression goes too far such as in creativity, symbols become unintelligible. If control is dominant, the created results are cold and uninspired. Those unable to experience such pleasurable activities related to creativity are threatened by the process of letting themselves go, which demands a sense of security (20).

Thus, regression is a process that can be used both defensively and nondefensively. One can imagine a continuum existing between normal and pathological uses of regression. When used non-pathologically, regression can enhance normal adult life and the empathic understanding of another.

\section{SPECULATIONS AND AREAS FOR FURTHER DEVELOPMENT}

After reviewing the non-pathological and pathological functions of identification and regression, I will now propose speculations concerning the use of these mechanisms in the empathic process. These are areas for further development that may expand the literature and theory of empathy. 
As discussed in my model, empathy is not solely based on identification, but rather is influenced also by regression. When used in the empathic process, regression of the therapist allows him/her to identify with the patient's phase-appropriate experiences and difficulties (Solky, C. Personal communication, 1994) as the therapist is influenced by his/her own childhood experiences. As we have seen in our discussions of identification and regression, childhood experiences and difficulties greatly influence functioning as adults and are thus cogent areas for understanding in psychodynamic psychotherapy. I agree that regression allows for phase-appropriate identification with the patient, and propose that regression allows the therapist to use his/her personal and professional experience to access phase-appropriate experiences productively for the patient. If regression were to not occur in empathy, identification involved would draw from a more narrow perspective of the therapist and would limit his/her basis of understanding. The therapist's controlled regression allows him/her to create another perspective of the patient when used with the identification process.

In my model I also propose that regression coupled with identification lets one use the learning process to aid development in another person. Identification used alone may develop a person as he/she takes in external information and begins to change him/herself. The addition of controlled regression in empathy allows one to view the phase-appropriate perspective of another, learn as the other models his/her perspective and experience, and then share this learned perspective with the patient when the regression is reversed. As the therapist shares his/her perspective of the patient, the patient learns and develops.

Finally, my model of empathy focuses on an interactive process where one takes from another and then gives back in a modified form after utilizing his/her experience and skills. New meanings of experiences are created by the two people involved as they learn, making empathy an artistic activity. Thus, regression in the service of the ego replenishes and nourishes the childhood wishes and wounds of the other, contributing to the healing process possible in psychotherapy and all relationships.

\section{REFERENCES}

1. Kohut H: Introspection, Empathy, and Psychoanalysis, in Search For the Self, vol 1. Edited by Ornstein PH, New York, Int Univ Press, 1978

2. Surrey JL: The "Self-in-relation:" A theory of women's development, in Women's Growth in Connection. New York, Guilford Press, 1991

3. Freud S: Group psychology and the analysis of the ego. The Standard Edition of the Complete Psychological Works of S. Freud, vol XVIII. London, The Hogarth Press, 1920, $105-110$

4. Greenson R: Empathy and its vicissitudes, Int J Psychoanal 1960; 41:418-424

5. Fleiss, R: The metapsychology of the analyst. Psychoanal Q 1942; 11:211-227

6. Jordan J: Empathy and self boundaries, in Women's Growth in Connection. New York, Guilford Press, 1991 
7. Freud S: Jokes and their relation to the unconscious. The Standard Edition of the Complete Psychological Works of S. Freud, vol III. London, The Hogarth Press, 1905

8. Winnicott DW: The Maturational Process and the Facilitating Environment. New York, Int Univ Press, 1965

9. Tansey MJ and Burke WF: Understanding Countertransference: From Projective Identification to Empathy. Hillsdale, NJ, The Analytic Press, 1989

10. Wolf, ES: Treating the Self: Elements of Clinical Self Psychology. New York, The Guilford Press, 1988

11. Basch MF: Understanding Psychotherapy: The Science Behind the Art. New York, Basic Books, 1988

12. Nadelson CC: Ethics, empathy, and gender in health care. Am J Psychiatry 1993; 150:1309-1314

13. Hamilton NG: Self and Others: Object Relations Theory in Practice. Northvale, NJ, Jason Aronson, 1990

14. Rogers C: On Becoming a Person. Boston, Houghton Mifflin, 1961

15. Brenner C: An Elementary Textbook of Psychoanalysis. New York, Anchor Books, 1974

16. Mack JE, Semrad EV: Theories of personality and psychopathology: Classical psychoanalysis in Comprehensive Textbook of Psychiatry. Edited by Freedman AM and Kaplan HI. Baltimore, Willimas and Wilkins, 1967

17. Piaget J: The Origins of Intelligence in Children. New York, Int Univ Press, 1952

18. Wong N: Theories of personality and psychopathology: Classical psychoanalysis, in Comprehensive Textbook of Psychiatry, $5^{\text {th }}$ ed, vol 1. Edited by Kaplan HI and Sadock BJ. Baltimore, Williams \& Wilkins, 1989

19. Brenner C: The Mind in Conflict. New York, Int Univ Press, 1982

20. Kris E: Psychoanalytic Explorations in Art. New York, Int Univ Press, 1952 